\title{
A case of macular hole formation by high-power laser pointer
}

\author{
Dorota Borowicz, Edyta Koman, Anna Matysik-Woźniak, Katarzyna Nowomiejska, Robert Rejdak \\ Department of General Ophthalmology, Medical University in Lublin, Poland
}

\begin{abstract}
Laser pointers are omnipresent. They are used in many spheres of life, e.g. education, medicine, industry, entertainment, and military. The number of reports of eye injury caused by laser pointers when used improperly is growing. We report a case of a 23-year-old man who had a full-thickness macular hole in the left eye after using an inappropriately high powered laser pointer. The patient was treated successfully with 23 -gauge pars plana vitrectomy. This case underlines the importance of careful and correct use of laser pointers because of the vision-threatening dangers induced by mishandling these gadgets.
\end{abstract}

KEY WORDS: laser pointer, retinal damage, macular hole

Ophthalmol J 2017; Vol. 2, No. 3, 79-82

\section{INTRODUCTION}

The term "laser" originated as an acronym for "light amplification by stimulated emission of radiation". The first laser was developed by Theodore Maiman in 1960. The beams of light produced by lasers are coherent, monochromatic, and unidirectional and they focused their power over small areas [1]. Nowadays laser pointers are available in many ranges of life. Laser instruments are used for medical (laser surgery), military, and industrial applications. Teachers use laser pointers to underline areas during visual presentations. These laser pointers are also often used as toys by children. There are an increasing number of reports of eye injury caused by laser pointers when used improperly. The retina is most sensitive to the laser radiation. The type of retinal damage is determined by the retinal location, and the duration and amount of energy delivered [2]. Laser radiation can injure the retina by photomechanical, photothermal, or photochemical mechanisms [3]. Retinal injuries, e.g. retinal pigment epithelium (RPE) changes; subretinal, intraretinal, subhyaloid, and vitreous haemorrhages, macular holes, or scarring are present after a laser incident. Fundus photography, fluorescein angiography (FA), optical coherence tomography (OCT), and perimetry are invaluable examinations to assess retinal lesions from lasers. Medical therapy for retinal injury after laser radiation is limited to corticosteroids on an indeterminate regimen.

This article describes the case of a patient with full-thickness macular hole formation by a high-power laser pointer, treated with pars plana vitrectomy.

\section{CASE REPORT}

A 23-year-old man came to the Department of Ophthalmology in Lublin in November 2016 due to complaints of diminution of vision in one eye for three weeks. The patient reported that he was exposed to the beam of a diode blue light laser three weeks previously. The device he used was a pointer with a maximum power rating of 50,000 $\mathrm{mW}$ and wavelength of $450 \pm 10 \mathrm{~nm}$ (Class III Laser Product) (Fig. 1). The laser light reflected from a mirror 


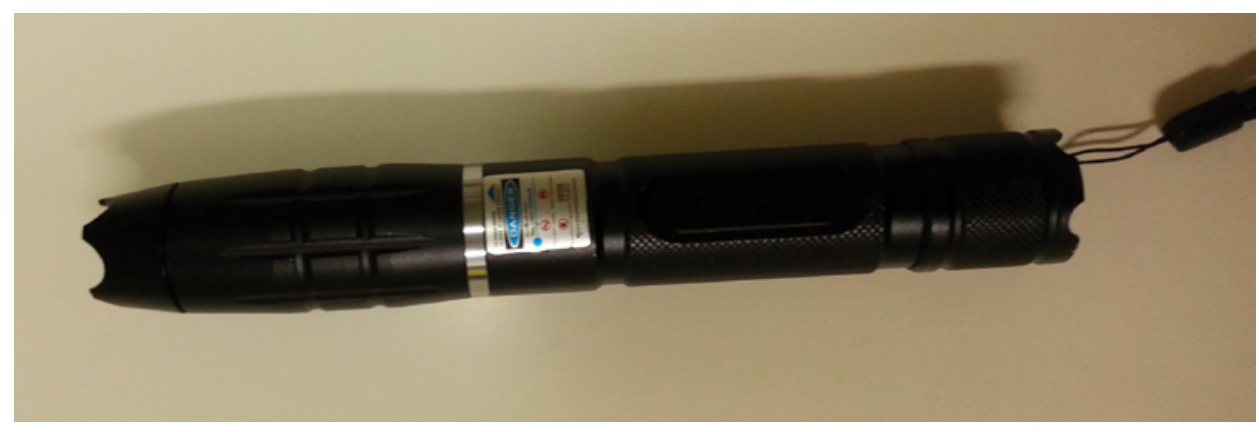

FIGURE 1. Blue light laser pointer used by the patient (Class III Laser Product)

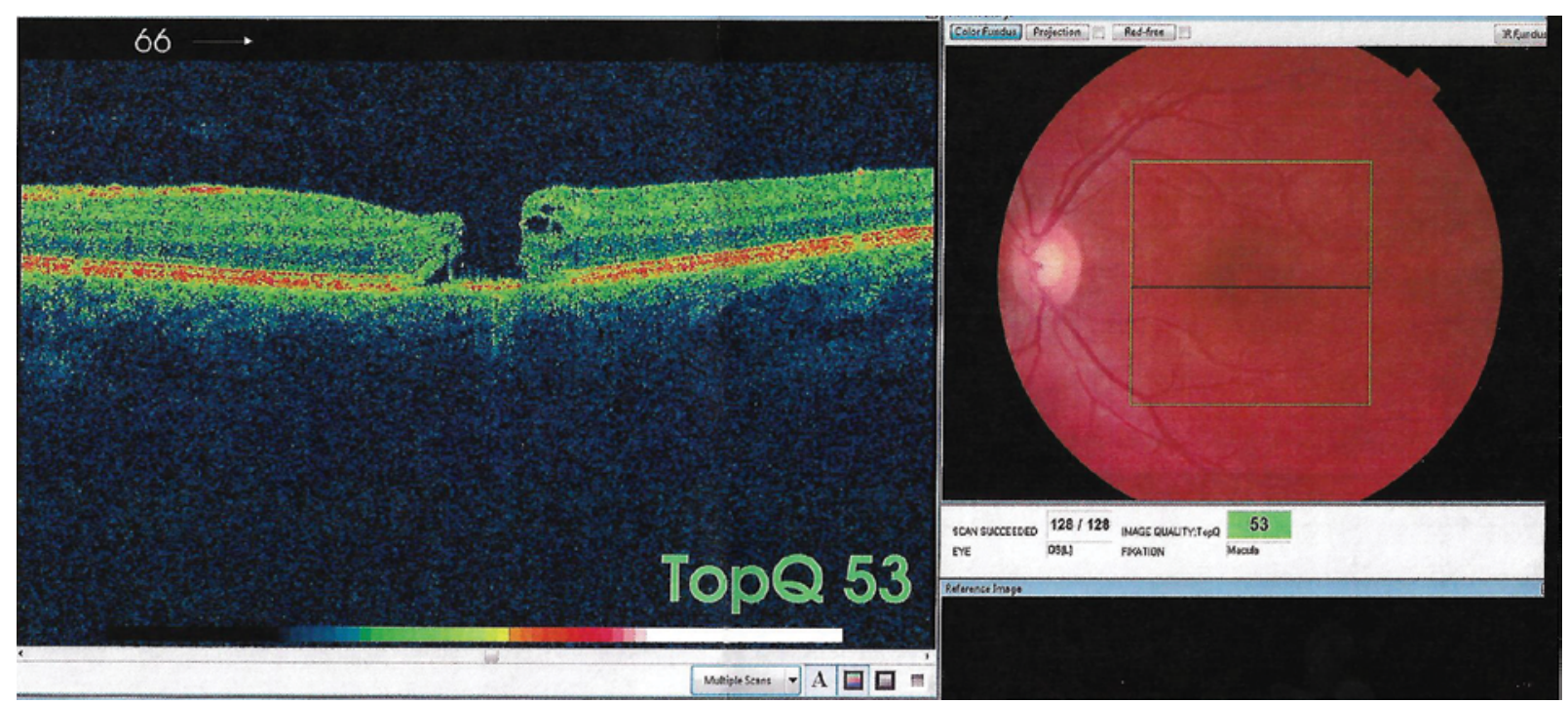

FIGURE 2. OCT showing large, full-thickness macular hole in left macula caused by laser beam

from a distance of $50 \mathrm{~cm}$ for an estimated $15 \mathrm{sec}$ onds. He looked once at the laser light. His vison was normal before this event in both eyes. He had observed a significant deterioration of vision in the left eye on the day after the event. He was admitted to the District Ophthalmology Hospital, where he received steroid treatment. There was no vision improvement after oral steroid treatment (prednisone, $1 \mathrm{mg} / \mathrm{kg}$ ). He presented to the Department of General Ophthalmology in Lublin three weeks after the event. His visual acuity was 1.0 in the right eye and 0.1 in the left eye. Slit-lamp biomicroscopy showed a normal anterior segment. Fundus examination revealed a macular hole in the left fundus; the fundus in the right eye was correct. The OCT three weeks after exposure showed a large, full-thickness macular hole with diminished retinal photoreceptor layer in the left eye (Fig. 2). On microperimetry (MAIA) analysis, fixation was central and stable and retinal sensitivity in the central was $28.9 \mathrm{~dB}$ in the left eye (Fig. 3). The patient was classified to vitrectomy. He was treated with 23-gauge pars plana vitrectomy with internal limiting membrane (ILM) peeling and 20\% SF6 gas tamponade. The visual acuity obtained during a first follow-up visit after two weeks was 0.4 in the left eye. The fundus examination revealed closing of the macular hole, which was confirmed in the OCT (Fig. 4). The patient remains under control in an ophthalmic clinic.

\section{DISCUSSION}

Nowadays laser pointers are easily available. Laser technology is evolving and these devices are becoming cheaper and more accessible. Laser pointers are popular among young people and among children as toys. There are a growing number of reports of eye injury caused by this equipment when used improperly [4]. The Food and Drug Administration (FDA) regulates the production of commercial laser products. The FDA recognises four major danger classes I to IV of lasers: 


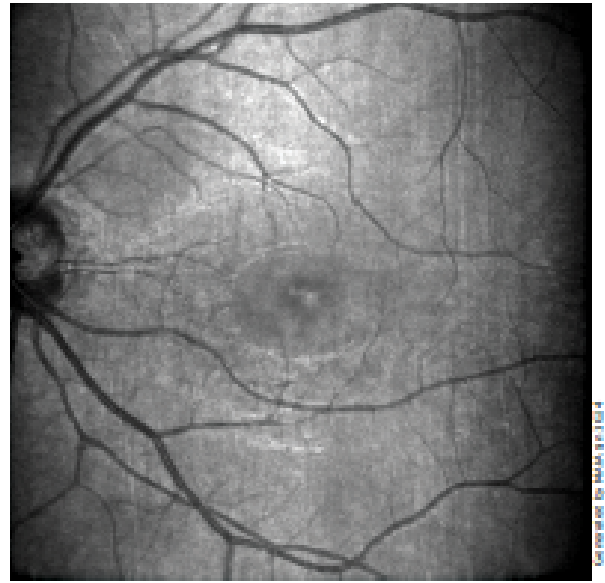

SENSITIVITY MAP

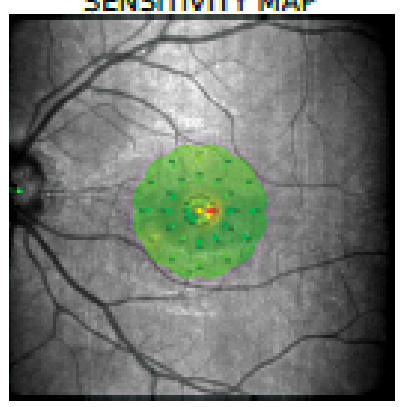

FIXATION PLOT

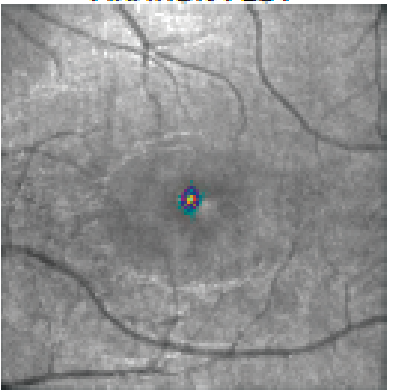

Bivarlete Cortour Ellpse Area:

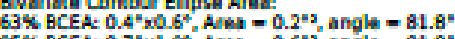

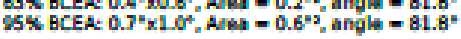

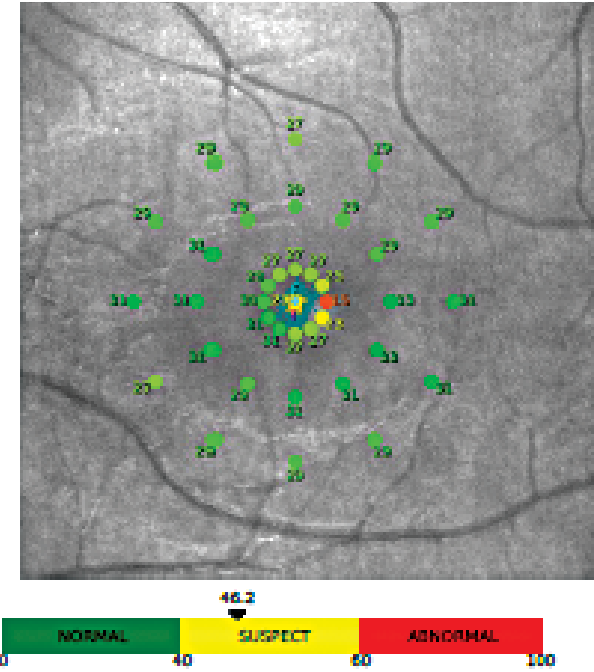

2B.

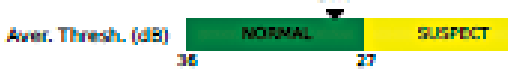

Histegram of Thessholds Fiequancles

C this rown
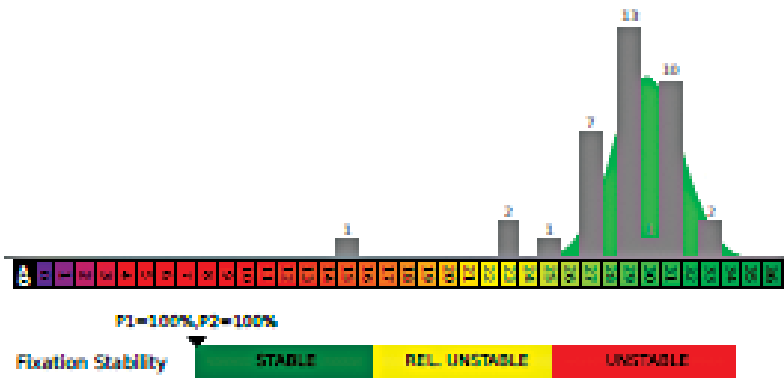

Fixation Groph

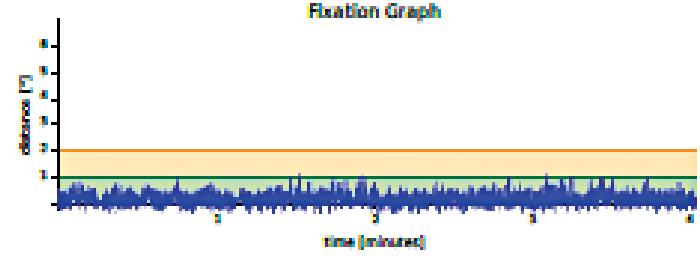

FIGURE 3. Microperimetry (MAIA) showing that fixation stability and retinal sensitivity in the centre was $28.9 \mathrm{~dB}$ in the left eye
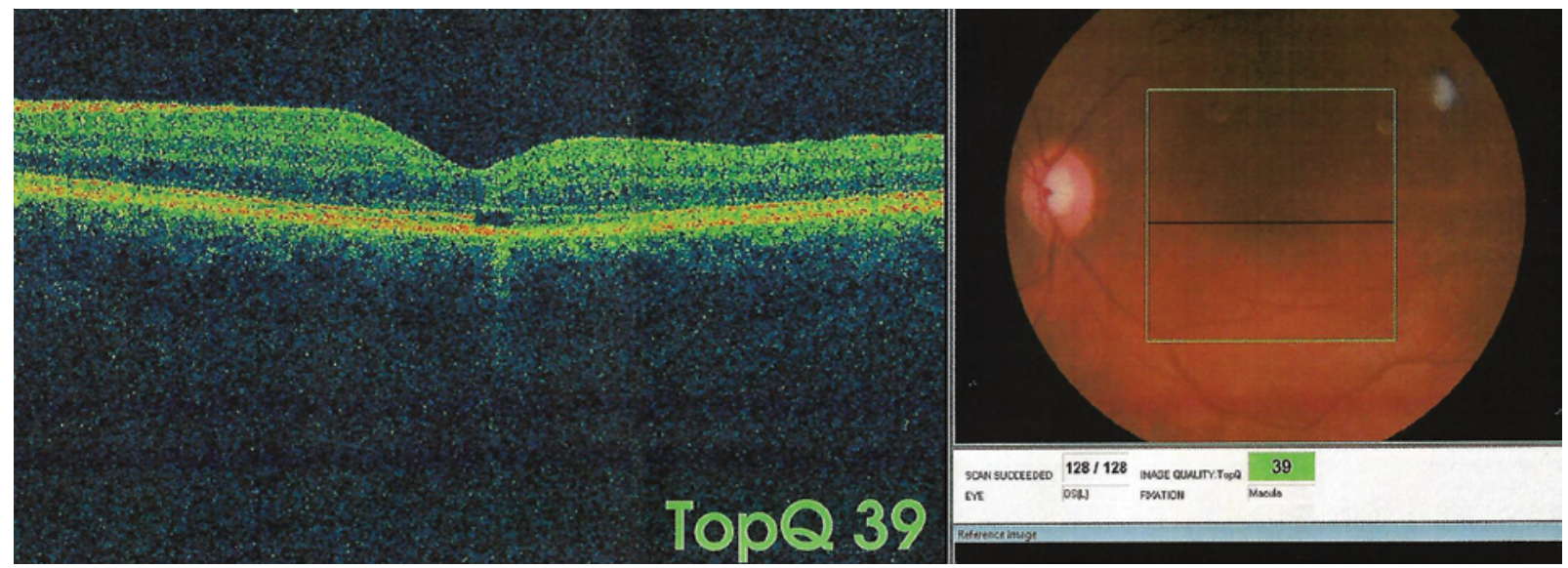

FIGURE 4. OCT of the left eye showing closed macular hole after vitrectomy 
- class I: output power $<0.5 \mathrm{~mW}$, lack of retinal damage - CD/ DVD players;

- class II: output power $<1.0 \mathrm{~mW}$ - danger of retinal damage increases when viewed directly for long periods of time - toys;

- class IIIA: output power $<5 \mathrm{~mW}$, danger of retinal damage depending on power and beam area - laser pointers;

- class IIIB: output power $<500 \mathrm{~mW}$, immediate eye danger when viewed directly — industrial laser, laser light show projectors;

- class IV: output power $>500 \mathrm{~mW}$, immediate eye danger - surgical laser.

The higher the class, the more powerful the laser and the potential to pose serious danger if used improperly. The laser products must have labels with the type of class. Class IIIA and II are the most popular types of laser [4].

The wavelength is connected with laser beam colour. Most laser pointers have a red colour, with wavelengths between 630 and $680 \mathrm{~nm}$. Green laser pointers emit a 490-575-nm wavelength. Blue laser pointers emit a 405-491-nm beam of light. Blue laser pointers are more damaging to the retina than green devices and green laser pointers are more dangerous than red devices [5].

According to Barkana and Belk, there are two categories of factors contributing to retinal damage from exposing to a laser: laser factors and patient factors. The laser factors are the wavelength of the radiation, pulse duration, and energy level of the beam. The patient factors are the size of the pupil (with injury being more severe in larger pupil sizes), the degree of retinal pigmentation (with darkskinned individuals suffering more severe injury than light-skinned ones), the proximity of the incident beam to the fovea, and the refraction status, with damage being more severe in emmetropic eyes due to the laser beam being more focused on the retina.

In the literature, retinal damage induced by laser pointers include perifoveal drusenoid deposits, subretinal haemorrhage, vitreous or chorioretinal haemorrhage, epiretinal membrane, retinal oedema, scars in the pigment epithelium, and macular hole [1, 6-8].

Current conventional medical therapy has variable results and it is mainly based on corticosteroids treatments [1, 9-11].

The pars plana vitrectomy can be successful in occlusion of the macular hole formation by laser pointer. Alsulaiman presented a retrospective ana- lysis of seventeen eyes of patients with macular hole formation by high-power handheld blue lasers. The mean patient age was 18 years. Fourteen patients were treated with 23 -gauge pars plana vitrectomy, internal limiting membrane (ILM) peeling, and gas or silicone oil tamponade. Twelve eyes had gas tamponade, and two eyes had silicone oil tamponade. The macular hole was closed in eleven cases. The macular hole was smaller in one eye of three unoperated eyes [12].

Qi presented a retrospective analysis of eleven cases with macular hole caused by laser. They were treated with vitrectomy, ILM peeling, and gas or silicone oil tamponade. All these macular holes closed after surgery [13].

In conclusion, macular holes due to the laser beam can be efficiently closed with surgery.

\section{REFERENCES}

1. Dirani $A$, Chelala $E$, Fadlallah $A$, et al. Bilateral macular injury from a green laser pointer. Clin Ophthalmol. 2013; 7: 2127-2130, doi: 10.2147/OPTH.S53024, indexed in Pubmed: 24204114.

2. Barkana $Y$, Belkin M. Laser eye injuries. Surv Ophthalmol. 2000; 44(6): 459-478, indexed in Pubmed: 10906379.

3. Mainster MA, Stuck BE, Brown J. Assessment of alleged retinal laser injuries. Arch Ophthalmol. 2004; 122(8): 1210-1217, doi: 10.1001/ archopht.122.8.1210, indexed in Pubmed: 15302664.

4. Farajpour S. A Case of Retinal Damage Caused by Green Laser Pointer. Advances in Ophthalmology \& Visual System. 2015; 2(5), doi: 10.15406/aovs.2015.02.00063.

5. Nakagawara VB, Montgomery RW. Laser pointers and aviation safety. Aviat Space Environ Med. 2000; 71(10): 1060-1062, indexed in Pubmed: 11051315.

6. Sayman Muslubaş I, Hocaoğlu $\mathrm{M}$, Arf $\mathrm{S}$, et al. Macular burns from nonmedical lasers. Turk J Ophthalmol. 2016; 46(3): 138-143, doi: 10.4274/tjo.29577, indexed in Pubmed: 27800276.

7. Wong R, Sim D, Rajendram R, et al. Class $3 A$ laser pointer-induced retinal damage captured on optical coherence tomography. Acta Ophthalmol Scand. 2007; 85(2): 227-228, doi: 10.1111/j.16000420.2006.00804.x, indexed in Pubmed: 17305745.

8. Jeon S, Lee WKi. Inner retinal damage after exposure to green diode laser during a laser show. Clin Ophthalmol. 2014; 8: 2467-2470, doi: 10.2147/OPTH.S68254, indexed in Pubmed: 25506208.

9. Raoof N, Chan TKJ, Rogers NK, et al. 'Toy' laser macular burns in children. Eye (Lond). 2014; 28(2): 231-234, doi: 10.1038/eye.2013.315, indexed in Pubmed: 24434663.

10. Dhoot DS, Xu D, Srivastava S. High-powered laser pointer injury resulting in macular hole formation. J Pediatr. 2014; 164(3): 668.e1, doi: 10.1016/j.jpeds.2013.11.019, indexed in Pubmed: 24373574.

11. Robertson DM, McLaren JW, Salomao DR, et al. Retinopathy from a green laser pointer: a clinicopathologic study. Arch Ophthalmol. 2005; 123(5): 629-633, doi: 10.1001/archopht.123.5.629, indexed in Pubmed: 15883281.

12. Alsulaiman SM, Alrushood AA, Almasaud J, et al. King Khaled Eye Specialist Hospital Collaborative Retina Study Group. Full-Thickness Macular Hole Secondary to High-Power Handheld Blue Laser: Natural History and Management Outcomes. Am J Ophthalmol. 2015; 160(1): 107-13.e1, doi: 10.1016/j.ajo.2015.04.014, indexed in Pubmed: 25892126.

13. Qi Y, Wang Y, You Q, et al. Surgical treatment and optical coherence tomographic evaluation for accidental laser-induced full-thickness macular holes. Eye (Lond). 2017 [Epub ahead of print], doi: 10.1038/ eye.2017.41, indexed in Pubmed: 28282068. 